\title{
Foreword
}

\section{Best Foot Foreword}

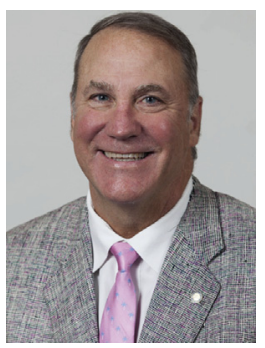

Mark D. Miller, MD Consulting Editor

It is a pleasure to introduce this issue of Clinics in Sports Medicine on Foot and Ankle Injuries and Treatment. I learned early in my sports medicine career that it is important to have a skilled foot and ankle surgeon on your team. Injuries to this area are common, and a special understanding of not only foot and ankle injuries but specifically sports foot and ankle injuries is critical for the successful management of these athletes. I am honored to have worked with many excellent foot and ankle surgeons, and the 2 coeditors of this issue of Clinics in Sports Medicine are no exception. I have been partners with Dr Park since his arrival at UVA 10 years ago. With his partners, he has taken care of athletes from the 2 major universities that we have the pleasure to serve, and he has been involved in numerous cases of knee dislocation with associated nerve injuries. I have also been lucky to have known and worked with Dr Kadakia for almost as long through numerous academic pursuits.

This issue covers the gambit of sports foot and ankle injuries. Excellent articles on fractures, ligament injuries, tendon injuries, and articular cartilage injuries are all included. I appreciate the "shout out" from both of the editors, but having been a guest editor myself, I assure you that they have "footed" the lion's share of the work. Thank 
you to the guest editors for putting together a great treatise on treating foot and ankle injuries in athletes.

Mark D. Miller, MD

Division of Sports Medicine

Department of Orthopaedic Surgery

University of Virginia

James Madison University

400 Ray C. Hunt Drive, Suite 330

Charlottesville, VA 22908-0159, USA

E-mail address:

MDM3P@hscmail.mcc.virginia.edu 